\title{
CD-1 mice show individual differences in nicotine preference in a modified two-bottle oral self-administration model
}

\author{
Junran Cao, Nicole M. Gautier and Ming D. Li* \\ Department of Psychiatry and Neurobehavioral Sciences, University of Virginia, Charlottesville, VA, USA
}

\section{Edited by:}

George Uhl, National Institute on Drug Abuse, USA

\section{Reviewed by:}

George Uhl, National Institute on Drug Abuse, USA

Frank S. Hall, National Institute on Drug Abuse, USA

${ }^{*}$ Correspondence:

Ming D. Li, Department of Psychiatry and Neurobehavioral Sciences, University of Virginia, 1670 Discovery Drive, Suite 110, Charlottesville, VA 22911, USA.

e-mail: ming_li@virginia.edu
Although both animal and human studies reveal significant contributions of genetics to smoking addiction, many human studies were underpowered or biased by potential confounding variables, and animal genetic studies are challenged by limited genetic variations and lack of convincing phenotypes. To address these concerns, we used non-sibling outbred CD-1 mice to evaluate individual differences in nicotine preference with a modified two-bottle oral self-administration model. Animals were first given free access to two bottles, one filled with nicotine dissolved in $2 \%$ saccharin and the other with saccharin only. Under this regular two-bottle choice condition, the majority of animals avoided the nicotine solution with limited individual differences. However, when we modified the model by introducing 4 days of exposure to $5 \%$ saccharin in the drinking water, the animals significantly increased nicotine consumption in the two-bottle choice test, with about $30 \%$ animals showing a nicotine preference. Nicotine preference after $5 \%$ saccharin treatment remained elevated throughout the 28 days of the experiment. Further, we found there existed striking individual differences in nicotine consumption after exposure to $5 \%$ saccharin, with a range of $0-100 \%$ of total liquid consumption. The enhanced individual differences and the ratio of nicotine consumption were observed at different concentrations of nicotine $(10-80 \mu \mathrm{g} / \mathrm{ml})$ and in both adolescents and adults. Further examination on the induction mechanism showed that the long-lasting nicotine preference was not correlated with nicotine consumption before the induction, $5 \%$ saccharin consumption, or weight gain during the induction. Although liquid consumption during the 4 days of $5 \%$ saccharin exposure was decreased by about $30 \%$, comparable liquid restriction alone for 4 days did not induce nicotine preference. Together, this study showed a strong and stable nicotine preference in CD-1 mice, which was induced by a short-term high concentration of saccharin in the drinking water. Considering the nature and heterogeneity of CD-1 mice, the striking individual differences imply that genetics plays an important role in nicotine preference observed in these animals.

Keywords: nicotine, oral self-administration, CD-1, individual differences, saccharin

\section{INTRODUCTION}

Genetic epidemiologic studies have revealed moderate to high heritability for smoking-related behaviors (Li et al., 2003; Xian et al., 2003; Lessov et al., 2004; Ho and Tyndale, 2007). However, the field is relatively lacking appropriate animal models that can compensate for potential confounding variables in human genetic studies. To identify susceptibility loci and genes for nicotine dependencerelated behaviors, a genetically variable population is preferred. Outbred animals, like unrelated humans, have numerous accumulated recombinations, and can offer significantly better mapping resolution than other traditional mapping populations. The CD1 mouse is an outbred line derived from a colony of Swiss mice started in 1926 (Rice and O'Brien, 1980). They are readily available from vendors such as Charles River and Harlan. Genetic variations in CD-1 mice support a complex genetic history similar to that of a human founder population, and the patterns of linkage disequilibrium are similar to those in wild-caught mice (Laurie et al., 2007; Aldinger et al., 2009). The CD-1 line has been applied to examine the inherent genetic variability for phenotypes such as ingestion (Lewis et al., 2006), stress reactivity (Touma et al., 2008), and lithium response (Gould et al., 2007). However, similar work on smoking-related behaviors has not been reported.

Another challenge for using animal model to study nicotine addiction-related behavior is that it requires a relatively simple and easy-to-implement procedure that allows quick processing of a large number of animals. Various animal behavioral models have been built to evaluate nicotine addiction. Oral self-administration with a two-bottle choice provides a self-controlled exposure to psychostimulants. This model can be set up quickly in each animal's home cage, which allows simultaneous testing of the large number of animals required for genetic screening and quantitative trait loci (QTL) mapping analysis. Strain differences among several 
inbred lines have been documented in oral nicotine consumption in mice (Meliska et al., 1995; Robinson et al., 1996), which suggests that genetic factors underlie oral nicotine consumption. However, the limitation of this model is that rodents under normal conditions do not show obvious nicotine preference, and animals usually are indifferent to or avoid nicotine solutions (Smith and Roberts, 1995; Robinson et al., 1996; Li et al., 2005), which makes it difficult to evaluate nicotine addiction. Although nicotine preference was observed with restricted daily access to water, the animals' normal drinking pattern was obviously changed, and animals went through daily nicotine withdrawal (Adriani et al., 2002a,b).

In the present study, we set up a model of nicotine preference by choosing outbred CD-1 mice and a two-bottle free choice. To observe nicotine preference, the model was modified by introducing an induction phase with a high concentration of saccharin. The mechanism for the induction effect was further investigated by examination of different ages of animals, physical changes, and correlation analysis among various physical parameters.

\section{MATERIALS AND METHODS \\ ANIMALS}

Male non-sibling CD-1 mice ordered from Charles River were maintained in a temperature $\left(21^{\circ} \mathrm{C}\right)$ and humidity $(50 \%)$ controlled room on a 12-h light-dark cycle (lights on 0700-1900) with unlimited access to food and liquid. All the animals were delivered on postnatal day (P) 23. They were habituated to the two drinking bottles as described below in their home cages for 5 days before the start of any experiment. The experiments for adolescent mice started on P29 and those for adults on P60. All experiments were carried out in accordance with the rules of the Institutional Animal Care and Use Committee at the University of Virginia and were consistent with Federal guidelines.

\section{DRUGS}

Nicotine free base (Sigma, St. Louis, MO, USA) was dissolved in $2 \%$ saccharin sodium (Sigma) and prepared freshly daily at pH 7.0.

\section{ORAL SELF-ADMINISTRATION GENERAL PROCEDURE}

Oral self-administration with 24-h free access was conducted in the home cages. All animals were housed individually. Two water bottles with fitted drinking tubes were placed in each cage at an equal distance from the food chamber. Each bottle contained about $20 \mathrm{ml}$ of liquid. During the nicotine two-bottle choice test, one bottle was filled with nicotine dissolved in $2 \%$ saccharin and the other with $2 \%$ saccharin only. The bottle locations were switched every day to avoid position preference. Animals were weighed, and the bottles were refilled at 10:00 AM-11:00 AM every day. Liquid consumption from each bottle was measured by reading the liquid volume and calculating the change every day. The water bottles were calibrated for fluid loss (evaporation and leakage) by placing them in a cage without animals. Liquid consumption from each bottle was calculated by an extraction of fluid loss. Induction was introduced in all of the following experiments. If there is no specification, animals were given only $5 \%$ saccharin in both water bottles for 4 days as an induction.

\section{EXPERIMENT 1: INDUCTION AND CONCENTRATION EFFECT}

Ten adolescent mice were given a two-bottle choice with nicotine $10 \mu \mathrm{g} / \mathrm{ml}$ for 4 days before the induction and for 12 days immediately after the induction. The concentration of nicotine was then increased to $20,40,60$, and $80 \mu \mathrm{g} / \mathrm{ml}$, each concentration being given for 4 days.

\section{EXPERIMENT 2: INDUCTION EFFECT ON DIFFERENT AGES}

To examine whether adolescent development is involved in nicotine consumption, 10 adolescent and 10 adult mice were given two-bottle choices with nicotine $40 \mu \mathrm{g} / \mathrm{ml}$ for 4 days before the induction and for 12 days after the induction. To keep a similar growing environment, we had the adult animals delivered as adolescents and raised in the same facility as the adolescent group.

\section{EXPERIMENT 3: SACCHARIN INDUCTION AND LIQUID RESTRICTION}

To examine whether water restriction could induce nicotine preference similar to that induced by $5 \%$ saccharin, this experiment included two groups of adolescents with 10 animals in each group. Both groups were given two-bottle choices with nicotine $40 \mu \mathrm{g} / \mathrm{ml}$ for 4 days before and after the induction. The change in liquid consumption during $5 \%$ saccharin induction is determined by comparing liquid consumption before and during the induction. A pilot study showed that animals during the induction drank $1 / 3$ less than before the induction. Therefore, one group was given $5 \%$ saccharin as an induction, whereas the other group was given $2 / 3$ of the normal amount of liquid. To further compare within each individual, the liquid-restricted group was given a second induction with $5 \%$ saccharin followed by a nicotine two-bottle choice for 5 days.

\section{DATA ANALYSIS}

The ratio of nicotine consumption was calculated as a percentage of total liquid consumption each day and averaged across days for the same concentration of nicotine. Nicotine consumption was calculated as micrograms per gram of body weight every day and averaged across days for the same concentration of nicotine (Meliska et al., 1995; Robinson et al., 1996). Data were analyzed with ANOVA followed by appropriate post hoc tests. Correlation analysis was conducted between the ratios of nicotine consumption after induction, with ratios of nicotine consumption before induction, 5\% saccharin consumption during induction, and weight gain immediately after 5\% saccharin. All animals $(N=30)$ from Experiments 1 and 2 were included in the correlation analysis.

\section{RESULTS}

EXPERIMENT 1: 5\% SACCHARIN INDUCED NICOTINE PREFERENCE AND INCREASED INDIVIDUAL VARIATION IN NICOTINE CONSUMPTION

Before 5\% saccharin induction, the average consumption ratio of nicotine $10 \mu \mathrm{g} / \mathrm{ml}$ vs. total liquid was less than $40 \%$ (Figure 1A). At this stage, only 2 of the 10 animals showed a modest nicotine preference. For the two nicotine-preferring animals, the average consumption ratios were 75 and 55\%, respectively (Figure 1B). After 5\% saccharin induction, the consumption ratio at the same concentration was increased, as indicated by a significant induction effect in a two-way repeated measures ANOVA for 


\section{A Average of Nicotine Consumption}
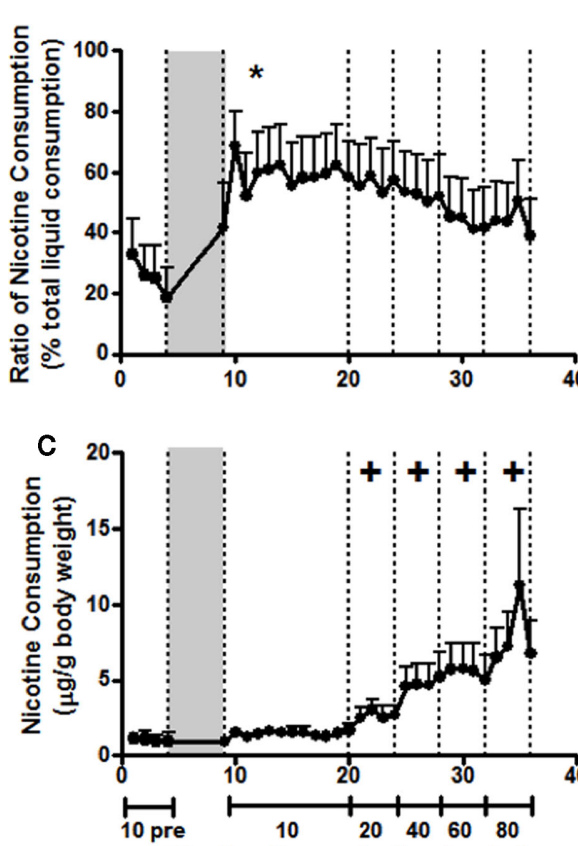

Nicotine Concentration ( $\mu \mathrm{g} / \mathrm{ml}$ )

\section{B Individual Nicotine Consumption}
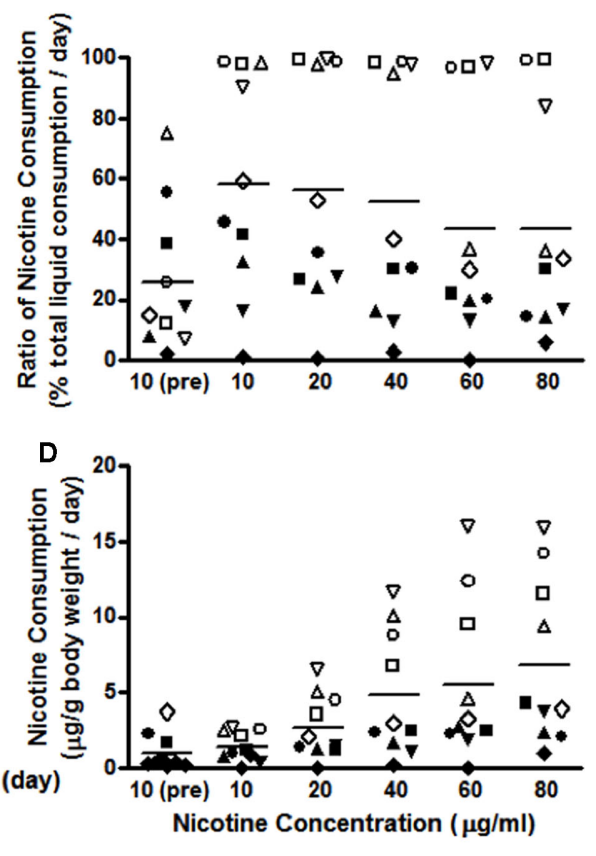

before the induction (10 pre) and were exposed to $5 \%$ saccharin in drinking water for 4 days [gray area in $(\mathbf{A}, \mathbf{C})$ ]. After induction, animals were given a two-bottle choice between nicotine $10 \mu \mathrm{g} / \mathrm{ml}$ and vehicle for 12 days, and then 4 days for each of the other concentrations. Note: ${ }^{*} p<0.05$ significant induction effect and ${ }^{+} p<0.05$ significant difference from $10 \mu \mathrm{g} / \mathrm{ml}$. The same symbols in $(\mathbf{B}, \mathbf{D})$ represent the data from the same animals. induction $\times$ day $\left(F_{1,9}=5.789 ; p<0.05\right)$. The consumption ratio remained elevated throughout the 12 days at $10 \mu \mathrm{g} / \mathrm{ml}$. Five of the 10 animals showed a nicotine preference, with four animals consuming the nicotine solution almost exclusively (Figure 1B). As the concentration increased every 4 days to $80 \mu \mathrm{g} / \mathrm{ml}$, nicotine preference decreased, which was reflected by a main concentration effect in a two-way repeated measures ANOVA for concentration $\times$ day $\left(F_{4,32}=6.271 ; p=0.001\right)$. However, post hoc analysis revealed no significant differences between any concentrations (Figure 1A). Three nicotine-preferring animals kept showing nicotine preference, whereas two switched from nicotine preference to aversion as the concentration increased (Figure 1B).

Animals consumed about $1 \mu \mathrm{g}$ nicotine per gram of body weight at the concentration of $10 \mu \mathrm{g} / \mathrm{ml}$, which was not significantly changed by $5 \%$ saccharin $\left(F_{1,9}=0.387 ; p=0.549\right)$ due to a decrease in liquid consumption (Figure 1C). Individual variation was within $5 \mu \mathrm{g} / \mathrm{g}$ before and after saccharin treatment (Figure 1D). Nicotine consumption increased significantly as the concentration increased (Figure 1C). This observation was confirmed by a significant concentration effect in a two-way repeated measures ANOVA for concentration $\times$ day $\left(F_{1.7,36}=8.616 ; p=0.004\right)$. The individual differences also increased with the concentration (Figure 1D). The upper limit was increased with the concentration and tended to reach a plateau at
$60 \mu \mathrm{g} / \mathrm{ml}$, at which animals drank as much as $16 \mu \mathrm{g} / \mathrm{g}$ every day (Figure 1D).

\section{EXPERIMENT 2: 5\% SACCHARIN INDUCED NICOTINE PREFERENCE AND INCREASED INDIVIDUAL DIFFERENCES IN BOTH ADOLESCENT AND ADULT MICE}

In Experiment 1, animals showed increased nicotine consumption from adolescence into adulthood. To examine whether adolescent development is involved in the induction of nicotine preference, we compared the induction effect in adolescents and adults. We chose a nicotine concentration of $40 \mu \mathrm{g} / \mathrm{ml}$, as Experiment 1 showed greater nicotine consumption and stable nicotine preference at this concentration (Figure 1). Unlike the situation with $10 \mu \mathrm{g} / \mathrm{ml}$, none of the animals showed a preference for $40 \mu \mathrm{g} / \mathrm{ml}$ before induction. The highest consumption ratios in both adolescents and adults were about $25 \%$ of total liquid consumption (Figure 2B). However, the ratio of nicotine consumption after $5 \%$ saccharin induction increased in both adolescents and adults without age differences (Figure 2A), as indicated by a significant induction effect $\left(F_{1,18}=36.23 ; p<0.0001\right)$, but not an age effect $\left(F_{1,18}=0.01487 ; p=0.9043\right)$ in two-way ANOVA for induction $\times$ age. After induction, the consumption ratios ranged from 0 to $100 \%$ in both adolescents and adults (Figure 2C). At each age, 4 of the 10 animals showed a nicotine preference. Although the 

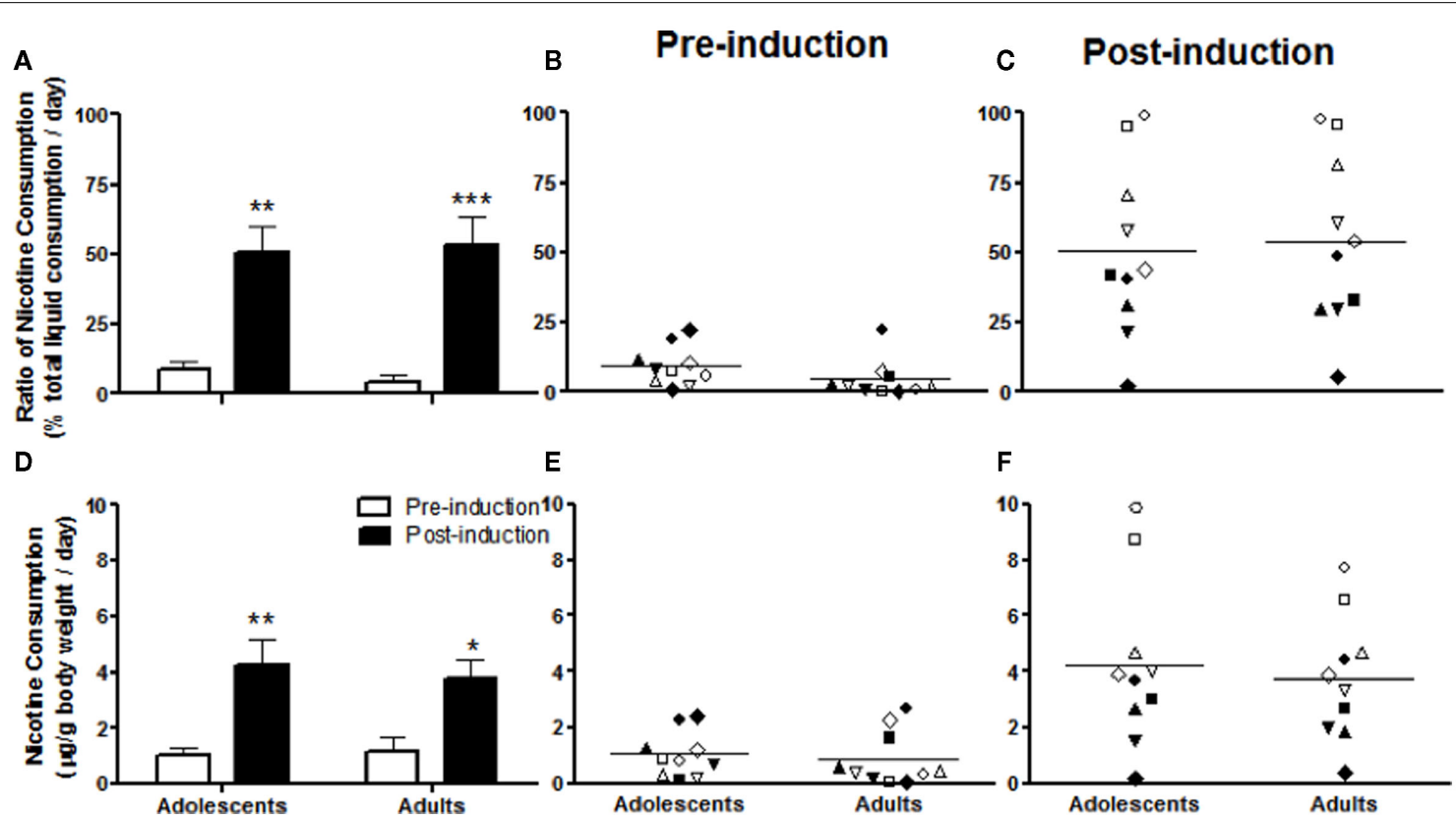

E

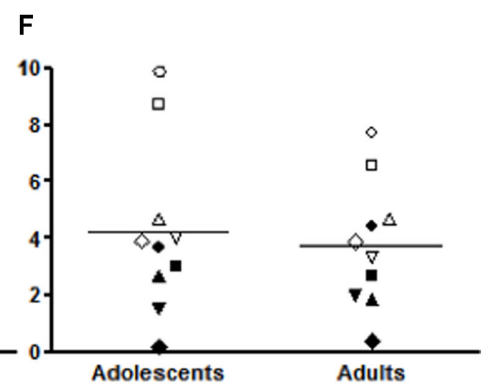

FIGURE 2 | Nicotine consumption before and after $\mathbf{5 \%}$ saccharin induction in adolescents and adults. The ratio of nicotine

consumption, calculated as the percentage of total liquid consumption (A-C) and nicotine consumption doses (microgram per gram of body weight) (D-F) are presented as average daily amounts across all animals
(A,D) and average daily values for each individual animal before (B,E) and after (C,F) induction. Note: ${ }^{*} p<0.05$ and ${ }^{*} p<0.001$ significantly different from pre-induction. The same symbols in pre-induction and post-induction of adolescents or adults represent data from the same animals (B,C,E,F). rest of the animals preferred vehicle to nicotine, the consumption ratios were also increased after induction (Figure 2C).

Nicotine consumption dose showed a pattern similar to that in the ratio of consumption (Figures 2D-F). The 5\% saccharin exposure significantly increased nicotine consumption $\left(F_{1,18}=18.14\right.$; $p<0.0005$, two-way ANOVA for induction $\times$ age $)$ in both adolescents $(p<0.01)$ and adults $(p<0.05)$ without age differences $\left(F_{1,18}=0.06748 ; p=0.7980\right.$, two-way ANOVA; Figure $\left.2 D\right)$. Both adolescents and adults consumed nicotine as much as $3 \mu \mathrm{g} / \mathrm{g}$ before saccharin induction (Figure 2E), whereas after induction, adolescents consumed as much as $10 \mu \mathrm{g} / \mathrm{g}$, whereas adults consumed as much as $8 \mu \mathrm{g} / \mathrm{g}$ (Figure $2 \mathbf{F}$ ).

\section{EXPERIMENT 3: INCREASED NICOTINE CONSUMPTION WAS NOT SECONDARY TO WATER RESTRICTION DURING INDUCTION}

During the 4 days of $5 \%$ saccharin induction, total liquid consumption decreased significantly $\left(F_{1,9}=41.932\right.$; $p<0.001$, twoway repeated measures ANOVA for induction $\times$ day; Figure $3 B$ ). To examine whether the greater nicotine consumption following $5 \%$ saccharin was secondary to limited liquid consumption, animals were treated by either water restriction or $5 \%$ saccharin for 4 days. The two groups of animals drank similar amount of liquid before $\left(F_{1,18}=0.127 ; p=0.726\right)$ and during $\left(F_{1,18}=1.361\right.$; $p=0.259$, two-way ANOVA for group $\times$ day) the induction period (Figure 3B). However, the water-restricted group drank significantly more water after induction than the $5 \%$ saccharin group $\left(F_{1,18}=8.752 ; p=0.008\right.$, two-way ANOVA for group $\times$ day $)$. The ratio of nicotine consumption showed a significant interaction of group ( $5 \%$ saccharin vs. water restriction) with induction (before vs. after induction; $F_{1,18}=10.798 ; p=0.004$; three-way ANOVA for group $\times$ induction $\times$ day; Figure $3 A$ ). The $5 \%$ saccharin exposure significantly increased the ratio of nicotine consumption $\left(F_{1,9}=10.004 ; p=0.011\right.$, two-way repeated measures ANOVA for induction $\times$ day), whereas water restriction had no significant effect $\left(F_{1,9}=1.632 ; p=0.233\right.$; Figure 3A). To compare the induction effect within the same animals, water-restricted animals were given $5 \%$ saccharin induction afterward. Similar to the findings in the other group, total liquid consumption was significantly reduced during $5 \%$ saccharin induction $\left(F_{1,9}=43.086 ; p<0.001\right.$; Figure 3B), and nicotine consumption increased significantly after the induction $\left(F_{1,9}=9.828 ; p=0.012\right.$; Figure $\left.2 \mathrm{~A}\right)$.

The body weights of the two groups of animals were similar before and after induction. Body weight decreased significantly during $5 \%$ saccharin induction $\left(F_{1,9}=16.122\right.$; $p=0.003$, twoway repeated measures ANOVA for induction $\times$ day; Figure $3 \mathrm{C}$ ). Although the water-restricted group tended to weigh less than the $5 \%$ saccharin group during induction, the difference did not reach significance $\left(F_{1,18}=3.916 ; p=0.063\right.$, two-way ANOVA for group $\times$ day). When the water-restricted animals were given 4 days of $5 \%$ saccharin afterward, the body weight decreased significantly $\left(F_{1,9}=5.346 ; p=0.046\right.$, two-way repeated measures ANOVA for induction $\times$ day), as observed in the other group.

\section{INDUCED NICOTINE PREFERENCE IS INDEPENDENT OF NICOTINE CONSUMPTION BEFORE INDUCTION, 5\% SACCHARIN CONSUMPTION, AND WEIGHT GAIN DURING THE INDUCTION}

The ratio of nicotine consumption after induction was not correlated with that before induction $(r=0.1158 ; p=0.5424)$ or 

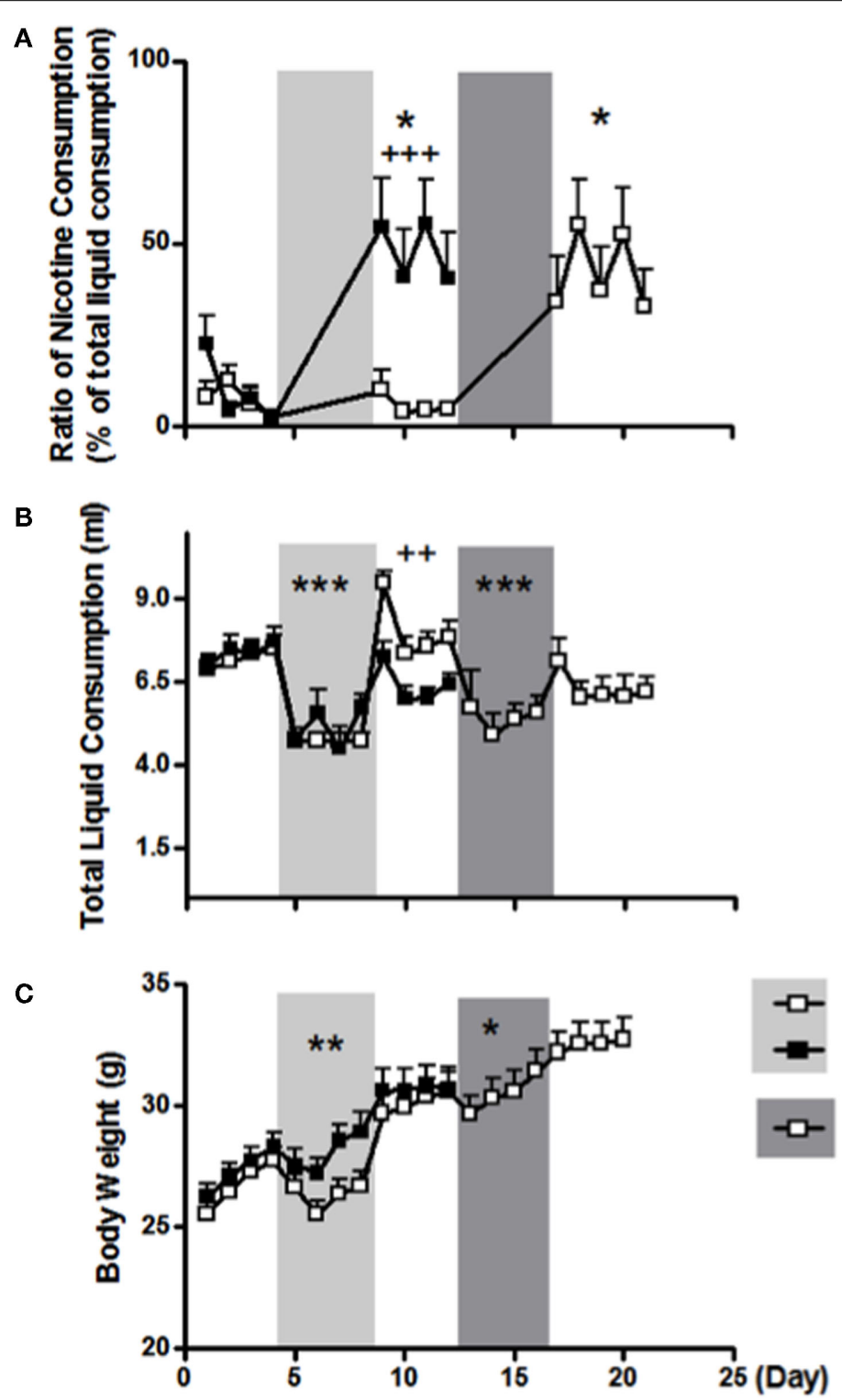

\section{Water Restriction}

$5 \%$ Sac

\section{$5 \%$ Sac}

FIGURE 3 | Comparisons of the effects of $5 \%$ saccharin and water restriction on nicotine consumption $(A)$, total liquid consumption $(B)$, and body weight (C). The percentages of all liquid consumption are presented as averages across all animals in water-restricted group (open symbol) and $5 \%$ saccharin group (closed symbol) on each day. Shaded areas represent induction stages. Note: ${ }^{*} p<0.05,{ }^{*} p<0.01$, and ${ }^{*}{ }^{*} p<0.001$ significantly different from pre-induction; ${ }^{++} p<0.01$ and ${ }^{+++} p<0.001$ significant difference between groups. with $5 \%$ saccharin consumption $(r=0.07880 ; p=0.6789)$ or body weight gain during induction $(r=-0.004982 ; p=0.9792)$. However, we observed a significant positive correlation between the ratio of nicotine consumption before induction and 5\% saccharin consumption during induction $(r=0.7932 ; p<0.0001)$.

\section{DISCUSSION}

Genetic factors contribute to smoking addiction, which is reflected in individual differences in various smoking-related behaviors. Similar to human beings, outbred animals are genetically varied. In the present study, we demonstrated different behaviors existed in response to nicotine in non-sibling CD-1 mice. Although mice do not normally show obvious nicotine preference through water bottles, a stable and strong preference could be induced by a short period of forced drinking of $5 \%$ saccharin. After the induction, striking individual differences were observed in nicotine consumption, with a range from complete avoidance to consumption of nicotine solution only. Given that we used non-sibling heterogeneous stock animals, genetic variation is likely to contribute to the striking individual differences observed in the nicotine consumption of these CD-1 mice.

\section{STABLE NICOTINE PREFERENCE INDUCED BY 5\% SACCHARIN IN DRINKING WATER}

We observed avoidance of nicotine by CD-1 mice under normal two-bottle choice conditions. Even after 30 days of two-bottle 
choices, none of the animals developed a preference for nicotine at concentrations ranging from 40 to $120 \mu \mathrm{g} / \mathrm{ml}$ (data not shown). This is consistent with previous reports that rodents, including various inbred lines and outbred stocks, do not normally show a nicotine preference through water bottles (Smith and Roberts, 1995; Robinson et al., 1996; Li et al., 2005). Although we did observe a few animals with a moderate preference for nicotine at a low concentration $(10 \mu \mathrm{g} / \mathrm{ml})$, the preference was not stable: it was most obvious on the first day and then changed to nicotine avoidance within the following several days. In contrast, after a short-term exposure to $5 \%$ saccharin, a very strong and stable nicotine preference was induced in about $30 \%$ of the animals. These animals drank almost entirely from the nicotine bottles from the first day after the induction, and the preference remained throughout the 28 days of the experiment. It appears to be a stronger preference than that seen under any other conditions such as prenatal nicotine exposure or restricted daily access to water (Meliska et al., 1995; Adriani et al., 2002a; Klein et al., 2003, 2004). Because the strong nicotine preference already reached about $100 \%$ at the lowest nicotine concentration tested, the ceiling effect may explain the plateau in the consumption ratios as nicotine concentration increased. At the same time, nicotine consumption doses increased in tandem with the nicotine concentration, which supports a concentration-dependent effect in the nicotine-preferring animals. We also observed that nicotine consumption doses were proportional to nicotine concentration in these animals, which may reflect the fact that nicotine consumption is limited by the daily liquid consumption. Another $10 \%$ of animals switched from nicotine preference to avoidance. This switch was more likely attributable to a concentration effect rather than a wearing off of the induction effect, as the switch was also observed on the ninth day after the induction as the concentration increased to $120 \mu \mathrm{g} / \mathrm{ml}$ (data not shown). The decrease in nicotine consumption ratio as nicotine concentration increased was also observed in the nicotine-avoiding animals. This concentration-effect correlation is consistent with previous nicotine oral self-administration behavior (Robinson et al., 1996). The nicotine-preferring animals may either be more sensitive to the rewarding effect or more tolerant of the aversive effect of nicotine or both after induction. Oral consumption of similar amounts of nicotine results in detectable plasma concentrations of nicotine and cotinine, the primary metabolite of nicotine (Adriani et al., 2002a; Klein et al., 2004; Theophilus et al., 2012), which suggests pharmacologic effects.

Although $30 \%$ of the animals developed a nicotine preference after induction at both 10 and $40 \mu \mathrm{g} / \mathrm{ml}$, our data suggest that the lower concentration will be a better starting concentration for animals to develop a strong and stable nicotine preference. This is consistent with the current strategies for inducing drug dependence in animals, which normally start with low concentrations. It also is similar to the development of smoking addiction, which usually starts as light smoking and gradually progresses to heavy use. Together, our findings indicate that $5 \%$ saccharin induction, combined with critical factors such as nicotine concentration range, can cause a stable and strong nicotine preference in the two-bottle choice model.

\section{MECHANISMS UNDERLYING THE INDUCTION EFFECT}

After short-term exposure to $5 \%$ saccharin, animals showed enhanced nicotine preference; suggesting that the high concentration of saccharin served as an inducing factor. The $5 \%$ saccharin did not simply magnify the individual differences, as the ratio of nicotine consumption before and after the induction did not correlate. In fact, the most obvious changes during 5\% saccharin induction were decreases in liquid consumption and in body weight. The decrease in liquid consumption is unlikely to induce nicotine preference, as liquid restriction alone did not have this effect. The lack of correlation between nicotine preference after induction and liquid consumption during induction further suggests that nicotine preference is not secondary to short-term of liquid restriction. Moreover, previous study suggested that water restriction on a daily basis is required to induce nicotine preference (Adriani et al., 2002a). The decrease in body weight during the induction is unlikely to induce nicotine preference, as there was no correlation between alterations in nicotine consumption and body weight. Moreover, even though animals lost weight during the induction, they recovered immediately afterward. Liquid consumption was still lower than normal even after induction. This is most likely to be secondary to an increase in nicotine consumption because the animals drank similar amounts of liquid when nicotine was not provided (data not shown). The decrease in liquid consumption is consistent with other report that nicotine consumption reduces water consumption (Grunberg, 1982; Bowen et al., 1986; Murrin et al., 1987; Robinson et al., 1996). Given that both adolescents and adults increased nicotine consumption after exposure to high concentration of saccharin, we conclude that the induction is independent of adolescent development.

The mechanism of induction is not fully understood. High concentrations of saccharin have been suggested to have a bitter taste, contrasting with the sweet taste at low concentrations (Schiffman et al., 1979; Dess, 1993; Horne et al., 2002; Damak et al., 2003). It is possible that a high concentration of saccharin alters the sense of taste, which is supported by the observation that $5 \%$ saccharin consumption during induction was positively correlated with nicotine consumption before but not after induction. On the other hand, $5 \%$ saccharin may directly change the central reward circuits and increase sensitivity to the rewarding effect of nicotine. Numerous studies have shown that previous exposure to natural reward or addictive drugs can cross-sensitize animals to other addictive substances through the common reward circuits (Itzhak and Martin, 1999; Biala and Weglinska, 2004; Clark and Bernstein, 2006; Avena et al., 2008). High concentrations of saccharin, despite the aversive taste, have strong rewarding, conditioned reinforcing, and memory-improving properties (Stefurak and van der Kooy, 1992). Therefore, it is likely that a high concentration of saccharin functions as an addictive substance, sensitizing the rewarding neuronal circuits.

\section{INDIVIDUAL DIFFERENCES IN NICOTINE PREFERENCE}

We observed significant individual differences in the induction of nicotine preference, in which $30 \%$ animals developed a stable preference for nicotine, $10 \%$ of the animals switched from preference to aversion, whereas $60 \%$ of animals showed stable nicotine 
avoidance. Although environmental factors such as those in the maternal care and breeding environment may be involved, the striking individual differences between 0 and $100 \%$ in nicotine consumption cannot be simply explained by these environmental factors. Moreover, we observed that the ratios of nicotine consumption after the induction ranged from 5 to $50 \%$ in inbred DBA mice and from 22 to 50\% in C57B6 mice. These individual differences in inbred lines are much smaller than CD-1 mice. Given the breeding history of CD-1 mice, it is highly likely that genetics factors contribute greatly to those observed individual differences. This is consistent with previous reports of strain differences in sensitivity to nicotine (Marks et al., 1986; Meliska et al., 1995; Robinson et al., 1996). Our observation also supports the view that individual differences resulting from genetic variation should be taken into account in toxicology, pharmacology, and basic research using outbred stocks (Chia et al., 2005). On the other hand, the individual differences suggest its application to genetic analysis of nicotine preference. Outbred animals has been emphasized in genetic analysis of complex traits (Chia et al., 2005; Flint et al., 2005). Compared with crosses from inbred lines, outbred stocks provide much higher mapping resolution for QTL

\section{REFERENCES}

Adriani, W., Macri, S., Pacifici, R., and Laviola, G. (2002a). Peculiar vulnerability to nicotine oral self-administration in mice during early adolescence. Neuropsychopharmacology 27, 212-224.

Adriani, W., Macri, S., Pacifici, R., and Laviola, G. (2002b). Restricted daily access to water and voluntary nicotine oral consumption in mice: methodological issues and individual differences. Behav. Brain Res. 134, 21-30.

Aldinger, K. A., Sokoloff, G., Rosenberg, D. M., Palmer, A. A., and Millen, K. J. (2009). Genetic variation and population substructure in outbred CD-1 mice: implications for genome-wide association studies. PLoS ONE 4, e4729. doi:10.1371/journal.pone.0004729

Avena, N. M., Rada, P., and Hoebel, B. G. (2008). Evidence for sugar addiction: behavioral and neurochemical effects of intermittent, excessive sugar intake. Neurosci. Biobehav. Rev. 32, 20-39.

Biala, G., and Weglinska, B. (2004). Calcium channel antagonists attenuate cross-sensitization to the rewarding and/or locomotor effects of nicotine, morphine and MK-801. J. Pharm. Pharmacol. 56, 1021-1028.

Bowen, D. J., Eury, S. E., and Grunberg, N. E. (1986). Nicotine's effects on female rats' body weight: caloric intake and physical activity. Pharmacol. Biochem. Behav. 25, 1131-1136.

Chia, R., Achilli, F., Festing, M. F., and Fisher, E. M. (2005). The origins and uses of mouse outbred stocks. Nat. Genet. 37, 1181-1186.

Clark, J. J., and Bernstein, I. L. (2006). A role for D2 but not D1 dopamine receptors in the cross-sensitization between amphetamine and salt appetite. Pharmacol. Biochem. Behav. 83, 277-284.

Damak, S., Rong, M. Q., Yasumatsu, K., Kokrashvili, Z., Varadarajan, V., Zou, S. Y., Jiang, P. H., Ninomiya, Y., and Margolskee, R. F. (2003). Detection of sweet and umami taste in the absence of taste receptor T1r3. Science 301, 850-853.

Dess, N. K. (1993). Saccharin's aversive taste in rats: evidence and implications. Neurosci. Biobehav. Rev. 17, 359-372.

Flint, J., Valdar, W., Shifman, S., and Mott, R. (2005). Strategies for mapping and cloning quantitative trait genes in rodents. Nat. Rev. Genet. 6, 271-286.

Ghazalpour, A., Doss, S., Kang, H., Farber, C., Wen, P. Z., Brozell, A., Castellanos, R., Eskin, E., Smith, D. J., Drake, T. A., and Lusis, A. J. (2008). High-resolution mapping of gene expression using association in an outbred mouse stock. PLoS Genet. 4, e1000149. doi:10.1371/ journal.pgen.1000149

Gould, T. D., O'Donnell, K. C., Picchini, A. M., and Manji, H. K. (2007). Strain differences in lithium attenuation of d-amphetamine-induced hyperlocomotion: a mouse model for the genetics of clinical response to lithium. Neuropsychopharmacology 32, 1321-1333.

analysis (Talbot et al., 1999; Valdar et al., 2006; Ghazalpour et al., 2008) and have been successful in susceptibility gene identifications (Yalcin et al., 2004, 2010). CD-1, a relatively cheap and easily available stock, has been suggested to be suitable for genome-wide association studies (Aldinger et al., 2009) and has been used to evaluate inheritable genetic variation for common laboratory and complex human phenotypes (Lewis et al., 2006; Gould et al., 2007; Touma et al., 2008).

In summary, we describe a modified nicotine oral selfadministration model, in which a long-lasting and stable nicotine preference could be induced by a short period of forced drinking of $5 \%$ saccharin. Moreover, non-sibling CD-1 mice showed striking individual differences in nicotine consumption, which indicates that great genetic differences exist among CD-1 mice and thus CD1 represents a valuable animal strain in genetic study of smoking addiction.

\section{ACKNOWLEDGMENTS}

This project is being supported by NIH grants DA-012844 and DA-013783 to Ming D. Li. We thank Dr. David L. Bronson for excellent editing of this manuscript.

Grunberg, N. E. (1982). The effects of nicotine and cigarette smoking on food consumption and taste preferences. Addict. Behav. 7, 317-331.

Ho, M. K., and Tyndale, R. F. (2007). Overview of the pharmacogenomics of cigarette smoking. Pharmacogenomics J. 7, 81-98.

Horne, J., Lawless, H. T., Speirs, W., and Sposato, D. (2002). Bitter taste of saccharin and acesulfame-K. Chem. Senses 27, 31-38.

Itzhak, Y., and Martin, J. L. (1999). Effects of cocaine, nicotine, dizocipline and alcohol on mice locomotor activity: cocaine-alcohol crosssensitization involves upregulation of striatal dopamine transporter binding sites. Brain Res. 818, 204-211.

Klein, L. C., Stine, M. M., Pfaff, D. W., and Vandenbergh, D. J. (2003) Laternal nicotine exposure increases nicotine preference in periadolescent male but not female C57B1/6 mice. Nicotine Tob. Res. 5, 117-124.

Klein, L. C., Stine, M. M., Vandenbergh, D. J., Whetzel, C. A., and Kamens, H. M. (2004). Sex differences in voluntary oral nicotine consumption by adolescent mice: a dose-response experiment. Pharmacol. Biochem. Behav. 78, 13-25.

Laurie, C. C., Nickerson, D. A., Anderson, A. D., Weir, B. S., Livingston, R. J., Dean, M. D., Smith, K. L., Schadt, E. E., and Nachman, M. W. (2007). Linkage disequilibrium in wild mice. PLoS Genet. 3, e144. doi:10.1371/journal.pgen. 0030144

Lessov, C. N., Martin, N. G., Statham, D. J., Todorov, A. A., Slutske, W.
S., Bucholz, K. K., Heath, A. C., and Madden, P. A. (2004). Defining nicotine dependence for genetic research: evidence from Australian twins. Psychol. Med. 34, 865-879.

Lewis, S. R., Dym, C., Ginzberg, M., Kest, B., and Bodnar, R. J. (2006). Genetic variance contributes to ingestive processes: a survey of mercaptoacetate-induced feeding in eleven inbred and one outbred mouse strains. Physiol. Behav. 88, 516-522.

Li, M. D., Cheng, R., Ma, J. Z., and Swan, G. E. (2003). A meta-analysis of estimated genetic and environmental effects on smoking behavior in male and female adult twins. Addiction 98, 23-31.

Li, X. C., Karadsheh, M. S., Jenkins, P. M., and Stitzel, J. A. (2005). Genetic correlation between the free-choice oral consumption of nicotine and alcohol in $\mathrm{C} 57 \mathrm{BL} / 6 \mathrm{JxC} 3 \mathrm{H} / \mathrm{HeJ} \mathrm{F} 2$ intercross mice. Behav. Brain Res. 157, 79-90.

Marks, M. J., Miner, L. L., Cole-Harding, S., Burch, J. B., and Collins, A. C. (1986). A genetic analysis of nicotine effects on open field activity. Pharmacol. Biochem. Behav. 24, 743-749.

Meliska, C. J., Bartke, A., McGlacken, G., and Jensen, R. A. (1995). Ethanol, nicotine, amphetamine, and aspartame consumption and preferences in C57BL/6 and DBA/2 mice. Pharmacol. Biochem. Behav. 50, 619-626.

Murrin, L. C., Ferrer, J. R., Zeng, W. Y., and Haley, N. J. (1987). Nicotine administration to rats: methodological considerations. Life Sci. 40, 1699-1708. 
Rice, M. C., and O'Brien, S. J. (1980). Genetic variance of laboratory outbred Swiss mice. Nature 283, 157-161.

Robinson, S. F., Marks, M. J., and Collins, A. C. (1996). Inbred mouse strains vary in oral self-selection of nicotine. Psychopharmacology (Berl.) 124, 332-339.

Schiffman, S. S., Reilly, D. A., and Clark, T. B. (1979). Qualitative differences among sweeteners. Physiol. Behav. 23, 1-9.

Smith, A., and Roberts, D. C. (1995). Oral self-administration of sweetened nicotine solutions by rats. Psychopharmacology (Berl.) 120, 341-346.

Stefurak, T. L., and van der Kooy, D. (1992). Saccharin's rewarding, conditioned reinforcing, and memoryimproving properties: mediation by isomorphic or independent processes? Behav. Neurosci. 106, 125-139.

Talbot, C. J., Nicod, A., Cherny, S. S., Fulker, D. W., Collins, A. C., and Flint, J. (1999). High-resolution mapping of quantitative trait loci in outbred mice. Nat. Genet. 21, 305-308.

Theophilus, E. H., Hayes, J. R., Potts, R. J., Ayres, P. H., Williams, C. D., and Garner, C. D. (2012). Toxicological evaluation of smokeless tobacco: 90-day rodent feeding studies. Exp. Toxicol. Pathol. 64, 15-24.

Touma, C., Bunck, M., Glasl, L., Nussbaumer, M., Palme, R., Stein, H., Wolferstatter, M., Zeh, R., Zimbelmann, M., Holsboer, F., and Landgraf, R. (2008). Mice selected for high versus low stress reactivity: a new animal model for affective disorders. Psychoneuroendocrinology 33, 839-862.

Valdar, W., Solberg, L. C., Gauguier, D., Burnett, S., Klenerman, P., Cookson, W. O., Taylor, M. S., Rawlins, J. N., Mott, R., and Flint, J. (2006). Genome-wide genetic association of complex traits in heterogeneous stock mice. Nat. Genet. 38, 879-887.
Xian, H., Scherrer, J. F., Madden, P. A., Lyons, M. J., Tsuang, M., True, W. R., and Eisen, S. A. (2003). The heritability of failed smoking cessation and nicotine withdrawal in twins who smoked and attempted to quit. Nicotine Tob. Res. 5, 245-254.

Yalcin, B., Nicod, J., Bhomra, A., Davidson, S., Cleak, J., Farinelli, L., Osteras, M., Whitley, A., Yuan, W., Gan, X., Goodson, M., Klenerman, P., Satpathy, A., Mathis, D., Benoist, C., Adams, D. J., Mott, R., and Flint, J. (2010). Commercially available outbred mice for genome-wide association studies. PLoS Genet. 6, e1001085. doi:10.1371/journal.pgen.1001085

Yalcin, B., Willis-Owen, S. A., Fullerton, J., Meesaq, A., Deacon, R. M., Rawlins, J. N., Copley, R. R., Morris, A. P., Flint, J., and Mott, R. (2004). Genetic dissection of a behavioral quantitative trait locus shows that Rgs 2 modulates anxiety in mice. Nat. Genet. 36, 1197-1202.
Conflict of Interest Statement: The authors declare that the research was conducted in the absence of any commercial or financial relationships that could be construed as a potential conflict of interest.

Received: 07 September 2011; accepted: 14 March 2012; published online: 30 March 2012.

Citation: Cao J, Gautier NM and $\mathrm{Li}$ $M D$ (2012) CD-1 mice show individual differences in nicotine preference in a modified two-bottle oral selfadministration model. Front. Psychiatry 3:28. doi: 10.3389/fpsyt.2012.00028

This article was submitted to Frontiers in Molecular Psychiatry, a specialty of Frontiers in Psychiatry.

Copyright (C) 2012 Cao, Gautier and Li. This is an open-access article distributed under the terms of the Creative Commons Attribution Non Commercial License, which permits non-commercial use, distribution, and reproduction in other forums, provided the original authors and source are credited. 